\title{
Achieving the design intent, reducing risk and saving costs of tailings storage facilities
}

\author{
JP Coffey Rio Tinto, Australia \\ JD Plunkett Rio Tinto, Australia
}

A Patel Rio Tinto, Australia

J Oliver Rio Tinto, Australia

M Gunner Rio Tinto, Australia

A Carneiro Rio Tinto, Australia

\begin{abstract}
The mining industry continuously strives to increase the effectiveness of tailings management practices to minimise impacts on people and the environment. A commonly stated objective of operations is to achieve the design intent, but is this clearly communicated by designers and understood by stakeholders? Planning, operating, monitoring and closing a tailings storage facility (TSF) can present many challenges, especially in dynamic mining environments where site conditions vary spatially and with time. However, big impacts can be made at relatively small cost once the tailings management system, design and performance are well defined and understood.

This paper presents various examples of initiatives aimed at achieving the design intent that have been adopted by Rio Tinto Iron Ore, which also reduce risks and improve tailings management performance. Examples presented include development and communication of short-term, long-term and life-of-facility deposition plans, implementation of simple deposition management tools, monitoring and managing slurry density, development and continual oversight of water balance models, and sound investment in water management infrastructure extending to safe performance in emergency situations. Regular governance was also implemented to provide assurance that these controls remain effective. These improvements also provide a financial benefit in the form of deferred capital expenditure due to the achievement of greater in situ densities of tailings deposits; a fortuitous by-product of following the principles within the Global Industry Standard on Tailings Management (GISTM) (Global Tailings Review 2020) and other industry guidance documents. As such, this paper aims to illustrate the benefits of continually improving tailings management practices with a focus on simple and in some cases novel approaches.
\end{abstract}

Keywords: tailings management, design intent, deposition, water balance, decant

\section{Introduction}

The management of a tailings storage facility (TSF) throughout its life is a complex task involving many technical disciplines and typically requiring consultation with a large and varied group of stakeholders. As the tailings industry moves further toward risk-informed management, it is becoming increasingly important that communications are clear between different parties who often have diverging interests. One inescapable thought is that a well-designed TSF can be operated such that unfavourable outcomes occur for all parties involved, and conversely, a well-operated TSF can result in similarly unfavourable outcomes due to a short-coming in the design. Consequently, a clear understanding between the designer, constructor and operator is key. Although it is doubtful the preceding statement would be considered controversial, such communications between parties often rely upon the use of the term 'design intent'. It seems most industry professionals have a detailed understanding of what the term 'design intent' is, however, as will be explored 
in this paper, it does not appear to be defined in any tailings guidelines. Therefore, despite being central to successful tailings management and requiring clear communication, it is currently left to each individual's interpretation. In the authors' experience, it does not seem that divergent views on significant elements of a TSF's design are common, but disagreement, especially during review and audit activities, are quite common.

Consideration of past TSF failures supports this view, with particularly catastrophic outcomes arising when also combined with poor change management practices. This is especially true when a complementary change in the design engineer or Engineer of Record (EoR) occurs. Such a change in personnel means that inherent knowledge and understanding of the sensitivity of the facility to different inputs can somewhat be lost. For example, consider the following unplanned events that are suggested to have contributed to the Fundão TSF failure (Morgenstern et al. 2016):

1. Damage to the original starter dam that resulted in increased saturation.

2. Deposition of slimes in areas where this was not intended.

3. Structural problems with a concrete conduit that caused the dam to be raised over the slimes.

Whether or not the intended operating parameters relating to each of the above events was effectively communicated in the operation, maintenance and surveillance (OMS) manual or otherwise, is not known. However, this is an example that suggests clear statements on the design intent of the facility could assist in highlighting the threat that each of these events pose.

Even though an industry-wide definition for the term 'design intent' is not available, there does appear to be many common elements that make up a design intent which are explored in this paper. After assembling a list of such elements, selected case studies are presented to demonstrate how risk and financial benefits can be realised by optimising operations of TSFs to implement practices aimed at achieving the design intent. In most cases, the intent is actually a continuum that can be exploited to the owner's benefit. For example, a goal of minimisation of the supernatant pond may be set. If it is achieved such that tailings beaches exposed to solar drying of $100 \mathrm{~m}$ is achieved, the facility may comply with all conventional design criteria. However, if a beach exposed to solar drying of 1,000 $\mathrm{m}$ length is achieved, the facility is not only more resilient to storm events, but in situ dry densities are also found to increase, which in turn presents financial benefits in the form of deferred capital expenditure for expansion of the TSF. This is through not only encouraging tailings desiccation and consolidation extending the facilities' life, but also through producing a strong, dense foundation enabling future raises.

All case studies presented in this paper are from Rio Tinto Iron Ore (RTIO) sites in the Pilbara region of Western Australia. The majority relate to operations of the TSFs since 2019 when a team of site tailings engineers was mobilised, and ongoing engagement of the designer as an EoR was established. Consequently, an increased focus was given to understanding the intricacies of the operation of each TSF and where benefits may present themselves. Management of the portfolio of TSFs has also been part of a program where initiatives are agreed and implemented at similar times on each site. A suite of data has resulted that allows some confident conclusions to be made which can serve to illustrate the benefits of understanding and implementing the design intent, not just in construction, but also when the greatest risk exposure exists, in operations.

\section{$1.1 \quad$ The design intent}

The term 'design intent' is routinely used within the tailings industry. Simplistically, its definition is easily comprehended, and its impact is powerful. However, a review of the literature has revealed that it is not clear how the term is meant to be applied. For example, Mining Association of Canada (2021) separate design intent from performance objectives and indicators, whereas narrower uses of the term can be found in GISTM (Global Tailings Review 2020) and Australian National Committee on Large Dams (ANCOLD 2019) with a focus on construction quality assurance. ANCOLD (2019) also refers to the design intent as an objective of operations via coverage in the OMS manual. GISTM (Global Tailings Review 2020) places compliance with the design at the core of the relationship between the Accountable Executive (AE), Responsible Tailings Facility 
Engineer (RTFE) and EoR. The Geoprofessional Business Association (2018) takes a similar stance, noting achievement of the design intent as key objectives for both the owner and EoR, but goes further in recommending quantifiable performance objectives being supplied in the OMS manual to enable assessing and reporting performance relative to the design intent. As such, it is clear there are few involved in tailings management who are not expected to understand and apply the design intent.

Although the use of the term appears to be with best intentions, none of the guidelines provide a specific definition. How can one then be expected to uphold the design intent as the key purpose of management and stewardship program if each individual may interpret its meaning differently? Whilst acknowledging that the design intent can vary on a site-by-site basis, it is suggested a more standardised approach as to what the design intent comprises would better serve the tailings industry during a time when the industry is striving to achieve global consistency through the application of the GISTM.

The most comprehensive control for this risk from the guides referenced above is found in the Geoprofessional Business Association (2018) guide due to its recommendation that quantified performance objectives are supplied in the OMS manual, however, it is also noted that a clear explanation of the design intent should be provided to the EoR if they are not also the designer. This suggests there may be further detail required to fully capture the design intent and perhaps how it needs to be reviewed if conditions change, whether intentional or not. In the authors' opinion, it does appear that understanding the design intent often requires familiarity with the collective knowledge of the facility, and as such, a designer is often best placed to articulate it in an exhaustive fashion. However, it is a reality that EoRs, and even owners, will change while the risk posed by a TSF will remain the same.

The computer aided design industry provides one possible definition that likely encapsulates many tailings engineers' use of the term: "Design intent is the motivations, rules and reasons behind design activities, and the capture, representation and transmission of design intent are of great significance to externalisation of tacit knowledge" (Liu \& Sun 2008). A similar example is provided by the International Organization for Standardization (ISO 2005): "Intentions of the designer of a model with regard to how it may be instantiated or modified". Even if such a definition was provided in tailings industry guidelines, the next required step would be to provide examples of where this should be used to aid risk controls and in which common tailings documents (e.g. design report, OMS manual, trigger action response plan (TARP)) it should be communicated. This is already achieved to varying degrees in most of the references provided above.

Another application of the term that the authors have routinely observed is by independent reviewers. Given the plethora of documents, models, instruments and processes incorporated within typical tailings management programs, it is often an opaque explanation to be told 'because it does not comply with the design intent' when questioning why an aspect of one's work does not pass muster. Can a third party truly know the designer's intent if it is not clearly articulated? If a constructor or operator is following all specifications, quality procedures and operating instructions, is it reasonable that they still may not comply with the design intent? In reverse, is a designer comfortable that if all its instructions are followed, an unacceptable threat to dam safety may remain because there is a key piece of information that was never communicated as a result of it not being covered by any section of the accepted suite of documents? It seems the common use of the term 'design intent' could be counter-productive whilst it is utilised in the absence of a clear definition.

\subsection{TSF construction}

Achieving or ensuring the design intent is an often noted goal and/or objective of construction activities, including GISTM (Global Tailings Review 2020) and ANCOLD (2019). Similar applications are also understood to be proposed for other guides under development at the time of writing. Geoprofessional Business Association (2018) goes slightly further, adding that quantifiable objectives should be provided. However, as discussed above, a definition of the design intent is not provided. From experience, it is noted that whilst few stakeholders enter a construction project with the intention of neglecting the design intent, historical 
evidence suggests that it is often not prioritised. This may happen for a variety of reasons, such as schedule and cost pressures, as well as stakeholders having variable goals.

The disconnect in the use of the term appears to present less risk for construction than in operations, as a package of construction documents such as a scope of work, drawings and specification is typically provided to the group responsible for construction. Therefore, if the suite of documents issued is comprehensive and arises from the design process, the design intent should be aptly captured. This is because the details in the construction documents would be based upon the same assumptions made in the design. Provided the group responsible for construction, be it a contractor or in-house crew, comply with the construction documents and there is a suitable quality assurance (QA) process in place to verify that this is the case, then the design intent should be achieved. Complications may arise where documentation is not sufficiently detailed to ensure design assumptions are carried through, however, this may be more probable on structural or mechanical (e.g. decant and piping) details rather than for impounding embankments.

As alluded to above, the design intent may also be directly referred to in construction contracts. As such, close attention to changes within contractual documentation must be made throughout the works, including the tender clarification phase prior to the construction commencing. Any changes agreed between the designer, contractor and owner should be clearly captured, documented and communicated to all stakeholders, with issued for tender and issued for construction documentation (typically a specification and drawings) updated as required. This may require updated design analysis and reporting.

Whilst decisions impacting the design intent can occur prior to construction commencing, given the fluid nature of any construction project, attentiveness must also be applied during construction through a formal management of change and technical query process involving the designer and operations representative, acknowledging that even minor changes made during construction could have significant impacts on the ability to achieve the design intent during the operational phase.

\subsection{TSF operations}

Achieving the design intent in operations is intrinsically connected to the OMS manual. As discussed in Section 1.1, most guidelines and standards outline an expectation that the OMS manual will contain a set of requirements that the owner must comply with. These requirements should consist of prescriptive indicators to ensure the facility will be operated in accordance with the design intent. However, it is not unusual to see the same requirements being applied to different facilities. This poses the question 'are the requirements an amalgamation of commonly recited 'rules of thumb' or are they direct outputs that align with meeting the design intent?'

Some typical prescriptive indicators, requirements and why they do not align with the design intent are summarised in Table 1.

\section{Table 1 Examples of common prescriptive operational requirements}

\begin{tabular}{lll}
\hline Requirements & Prescriptive indicator & Inconsistency aligning with the design intent \\
\hline $\begin{array}{l}\text { Deposit tailings in } \\
300 \mathrm{~mm} \text { lifts }\end{array}$ & $\begin{array}{l}\text { Rotate spigots every four } \\
\text { days }\end{array}$ & $\begin{array}{l}\text { Variable flow occurs in each operating spigot } \\
\text { Variable flow occurs in the plant } \\
300 \mathrm{~mm} \text { can be deposited in one day or seven } \\
\text { days }\end{array}$ \\
$\begin{array}{l}\text { Monitor survey } \\
\text { prisms weekly }\end{array}$ & Trigger level set at $10 \mathrm{~mm}$ & $\begin{array}{l}\text { Tolerance of survey instrumentation } \\
\text { as-designed limited to } 25 \mathrm{~mm} \text { or not considered }\end{array}$ \\
$\begin{array}{l}\text { Return water } \\
\text { minimum rate }\end{array}$ & Average $300 \mathrm{~m}^{3} / \mathrm{h}$ & $\begin{array}{l}\text { Decant design assumes } 100 \% \text { utilisation. Not } \\
\text { aligned with process design criteria }\end{array}$ \\
\hline
\end{tabular}


Improvements in key operating key performance indicators which culminate in de-risking the water balance and increasing achieved in situ dry densities require unique solutions for each TSF. In some cases, affecting such changes can be relatively simple and aided by collaboration between the designer and operator, which can also magnify the benefits.

\subsection{TSF governance}

The use of the term design intent in governance activities appears quite pervasive. For example, the Department of Mines, Industry Regulation and Safety (2021) in Western Australia refer to the design intent as a reference point for auditing during operation and maintenance phases of an asset. Interestingly, the term is not used in a similar fashion in any of the most commonly referenced tailings industry guidelines, although it is logical as it is referred to as important information to be communicated in construction and operational documents, as discussed earlier. Although application of the term appears to be quite a valid use of the idea, it may not be practical if not widely understood and applied in the same manner. If one refers to the ISO (2005) definition supplied in Section 1.1, it appears the design intent relates to the designer's intentions. In practice, can all such intentions be objectively stated? It could be argued that an exhaustive list may not be possible as several of the engineering disciplines that substantially impact the design of a TSF require well-developed engineering judgement in order to make use of often incomplete information. However, given the uniqueness of each TSF and the site upon which it is constructed, and the success of the designer to understand and apply all of this information in the vast majority of cases, it seems that a clear statement of the design intent that enables enhanced and risk-informed governance of a TSF is possible and is likely already occurring. This would only be enhanced by a common definition of the term for use in practice.

\section{Methodology}

The benefits of prudent operational improvements will be demonstrated through presentation of several case studies. Each is aimed at showing how the design intent may be achieved during operations. However, as highlighted earlier, in absence of an accepted and widely employed definition of the term 'design intent', the authors have first had to present common elements they have observed given their experience and/or are supplied for various facilities within the portfolio. Additional quantified performance objectives that the team has worked to implement in recent years are also added to this list, as they are thought to align well with the design intent of each facility.

\section{Overview of common design intent}

In absence of clear, comprehensive guidance on how to meet the design intent, the authors have collectively developed the following common goals for TSF management that they consider to be fundamentals or closely associated with typical design intent elements. Where they are closely associated, uncertainty arises as these elements may also be considered a performance indicator and thus a metric used to judge the success of achieving the design intent.

A typical design intent witnessed across the industry:

1. Comply with the design requirements or various guidance documents.

2. Achieve minimum Factors of Safety for slope stability.

3. Demonstrate safety against internal erosion.

4. Satisfy risk-based hydrological design criteria, whether surplus water is intended to be stored or released through spillways.

5. Minimise surface and interstitial water storage to tolerable limits (volume and location of saturated zones) which validate boundary condition assumptions utilised in modelling. 
6. As a corollary to five, maintain zones of saturation within impounding structures and foundations below design assumptions.

7. Deposit tailings in thin-lifts to maximise in situ dry densities.

8. Deposit tailings in a sequence that limits the probability of the supernatant pond migrating to a location that may pose a threat to the stability of an impounding structure.

Some other less-seen aspects of the common design intent that have been promoted in recent years at RTIO include:

1. Achieve a minimum slurry density at the process plant to maximise the probability of achieving five, and optimise achieved in situ dry densities, and in effect limit rate-of-rise.

2. Accurately report volume of deposited dry tailings and compare them against design assumptions and operational plans.

3. Achieve decant rates from the supernatant pond to support five.

4. Maintain a sufficient pond depth to allow continuous decant operations and define when a pump needs to be turned-off to avoid damage.

\subsection{Additional operating goals}

Commonly, additional operating goals are also stated within the OMS manual. Examples include:

1. Compliance rate on the completion of inspections.

2. Maintenance of phreatic surface below trigger levels.

3. Measurement of displacements to ensure movements are below trigger levels.

4. Various metrics testing engagement of operations personnel.

Each of the above tasks/measures aims to ensure the typical design intent is achieved. In some cases, several elements are tested or partially tested by one operational goal. However, it is important to note that whilst these elements serve to enable or assure the achievement of the design intent, they are not physical elements of a TSF directly related to dam safety. Rather, they may be considered key aspects of the frontline component of a governance program. In isolation, achievement of these metrics does not assure the safety of a TSF, unless they are related to ensuring the design intent is achieved and maintained within operations.

\section{$4 \quad$ Case studies}

This section presents several case studies where one or more of the typical design intent elements listed in Section 3 have been achieved during operations. In some instances, quite novel approaches were taken, and in others, improved communication and management of well-established approaches were employed. Most of the case studies have occurred since late 2019 when RTIO deployed several site-based tailings engineers. As such, these case studies also serve to demonstrate what can be achieved when personnel with advantageous skills and experiences are empowered to take a leadership role in the management of a TSF. Mobilisation of these tailings engineers was supported by implementation of ongoing external technical support, typically of EoR. In many ways, having such a personnel structure allows for constant communication and work towards achieving the design intent; an efficient workaround if not a complete solution to the complications discussed in Section 1.1.

\subsection{Slurry density management}

The thickener underflow slurry density is an integral variable that drives the water balance, deposition planning (beach profiles and pond location), and decant infrastructure requirements. If the TSF is not 
appropriately modelled and included in the site water balance, there may not be an appreciation of the required design elements necessary to meet the design intent.

Typically, the processing requirements of a TSF is provided by the owner's processing team to the designer consisting of the minimum and maximum set points that are achievable within the thickener and the water demand required for the process tanks. Subsequently, these set points are then used to inform a conservative water balance, decant infrastructure (focus on maximum flow rate and maximum solids content in the supernatant pond), and tailings transport system (focus on range of flow rates and maximum solids content), thus establishing the upper and lower bound performance indictors needed for operations.

However, should the plant demand and overall site water balance be excluded from this assessment, constraints during operations will present themselves, and that can have an impact on the average achieved density required to meet the design intent. Some of the operational constraints that have been observed to have a detrimental impact on achieved dry density and rectifications that have been employed are included in Table 2.

\section{Table 2 Operational issues impacting slurry density and potential solutions}

\begin{tabular}{|c|c|}
\hline Operational issues & Rectification \\
\hline $\begin{array}{l}\text { Change in set points or programmable logic } \\
\text { controller to improve other areas in the plant }\end{array}$ & $\begin{array}{l}\text { Standardisation of control logic across all assets } \\
\text { to ensure consistency in the processing } \\
\text { requirements }\end{array}$ \\
\hline $\begin{array}{l}\text { Limited awareness by plant operators on the } \\
\text { implications of additional water being flushed } \\
\text { from the process water tanks to the TSF }\end{array}$ & $\begin{array}{l}\text { Introduced engineering set points, hard coded in } \\
\text { the process logic control for the high and low } \\
\text { levels within the process water tanks }\end{array}$ \\
\hline $\begin{array}{l}\text { Interdependency of the plant system requiring } \\
\text { both raw water and decant water to maintain } \\
\text { production }\end{array}$ & $\begin{array}{l}\text { Decoupled the process and raw water systems to } \\
\text { remove the reliance on either system }\end{array}$ \\
\hline $\begin{array}{l}\text { Malfunctioning process infrastructure (i.e. valves } \\
\text { and solenoids that contribute to excess water) }\end{array}$ & $\begin{array}{l}\text { Introduce flowmeters around the plant to } \\
\text { provide visibility on potential items that can } \\
\text { contribute to excess water being introduced, and } \\
\text { regular maintenance tactics }\end{array}$ \\
\hline
\end{tabular}

An example of the benefits that have been realised at Site $A$ are illustrated in Figure 1, which shows performance over the timeline since there has been a tailings engineer at the site able to dedicate time to tracking slurry density and assisting the plant team in scoping and implementing improvement initiatives.

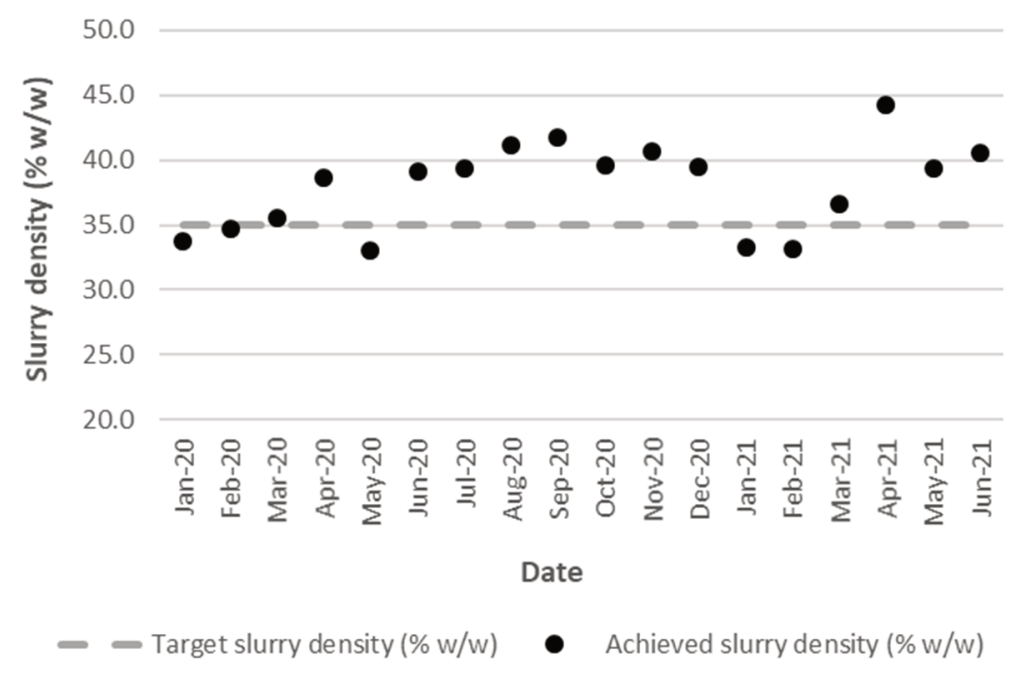

Figure 1 Example of improved deposition slurry density 
One specific example of such an improvement initiative currently underway is related to thickener control via automation of the process. Water recovery at the process plant is increased when clarified overflow from the thickener is maximised, resulting in less water being pumped to the TSF and myriad advantages that are discussed throughout this paper. Automation of thickener control to achieve the design intent has been identified as an important process.

The pre-existing interface detection system required manual operation and often inaccurately described the true level of each zone within the thickener. As such, an automated process control system was introduced. While the details of automated process control are beyond the scope of this paper, its goal is to more accurately define the different layers in the thickener and manipulate the flow set-point based on individual constraint controllers for rake torque, bed pressure, compacted bed level and underflow density. In addition, the control logic manipulates the flocculant flow set-point based on the action of individual constraint controllers for settling band, clarity, and settling time.

\subsection{Deposition planning and implementation}

Planning of deposition is important to support several of the common elements of design intent discussed previously. Simply stated, without careful planning and execution, it is easy to fall into the traps of having too much water under, within and on top of the tailings mass, and too close to impounding structures or sensitive receptors, if groundwater level and/or quality are a concern. Although the theory is generally quite simple, the coordination required to realise successful tailings deposition planning is often complex. Information transfer is key to achieving the deposition plan and requires clear directions provided to operations staff. At all sites, this is achieved through structured annual and three-monthly updated plans developed with the EoR which are then simplified to Excel-based weekly plans delivered to the operational team by the site tailings engineer. These plans are updated continually to account for unexpected changes, such as unplanned outage of the plant or malfunctioning of tailings delivery equipment. Tracking is then completed through daily department meetings, and confirmation is achieved from the daily inspections requiring operational spigot numbers to be recorded. An overall deposition plan and vigilant management is required continuously. This can be achieved through the implementation of carefully developed and well communicated processes.

Site $B$ is a cross-valley TSF with deposition from the outer-reaches of the basin and the impounding embankment. The design intent was for deposition through four to six spigots to achieve $200 \mathrm{~mm}$ tailings lifts. Upon commissioning, deposition was conducted through a single open-ended spigot and locating the pond remote from the decant tower which was constructed in a small side-valley. This resulted in decant not being possible for a number of years. Since the deployment of a site tailings engineer and implementation of detailed deposition planning, the length of dry tailings beaches from the embankment have increased from under $100 \mathrm{~m}$ to over $500 \mathrm{~m}$. As will be discussed further in Section 5 , the in situ density of the tailings have also increased.

Deposition plans should be formed based on the current state of the TSF, life-of-mine plan, closure requirements and intended landform. Site $C$ is a historical TSF where the original design intent, which was successfully implemented for 22 years, was to recover water using decant towers adjacent to the main embankment, a $34 \mathrm{~m}$ tall water-retaining dam. The facility subsequently underwent a significant change in operating strategy to implement a centre-line raise of its main embankment. This required depositing from the main embankment and relocating decant to approximately the centre of the facility, which was supported by installing a central dividing embankment.

The OMS manual of the TSF requires $300 \mathrm{~mm}$ tailings lifts, evenly sloped beaches, and five spigots to be operated at any one time. These relatively generic design intents have been carried over through multiple revisions of the OMS manual and change in designers. However, there is no detailed guidance in the OMS manual of how it can be achieved with variability in plant output. Two examples from the OMS manual are:

1. Tailings must be deposited into the TSF through systematically cycled sets of five spigots from around the TSF perimeter. It is important to deposit in thin layers of tailings (less than $300 \mathrm{~mm}$ ) whilst maintaining a decant pond adjacent to the decant pump. 
2. The flow rate should be monitored by operations personnel, and if the flow rate exceeds the design flow rate of $170 \mathrm{t} / \mathrm{h}$, or if channelling or erosion is observed, additional spigots should be opened to reduce the flow rate.

The deposition flow rates at Site $\mathrm{C}$ are $200-700 \mathrm{~m}^{3} / \mathrm{h}$, and the outlet velocity is relatively high, causing channelling and erosion of the upstream slopes despite operating with six open spigots. Flow was only achieved from the first two to three spigots in the line; therefore, the OMS manual requirement could not be physically achievable, and as such, the design intent was not achieved. To overcome these issues, pinch and $V$-port valves have been installed to throttle flow. Multiple benefits were gained using these valves including:

1. Distribution of flows to approximately 10 spigots at a much more even distribution than the design intent whilst achieving similar flow rates.

2. Mitigation of erosion of the upstream face and consequently reducing the risk of piping initiation.

3. Mitigation of craters forming on the beach causing an uneven beach and uncontrolled flows.

4. Reduction in segregation and steepening of beach slopes reducing the risk of rapid ponding against embankments.

5. Improvement in pond control with greater redundancy.

Deposition plans at Site $\mathrm{C}$ are supported by quarterly survey through use of drones. Survey data is supplied to the EoR for analysis of beach formation/slopes, pond areas/volumes, in situ density, remaining capacity and freeboard, detailed contours, and additional lift thickness to achieve the planned life-of-mine profiles. The site tailings engineer subsequently collates the information and updates the deposition plan for the next quarter with consideration of other plant operation inputs such as maintenance shutdown plans, TSF maintenance and plant throughput.

A simple yet effective method of ensuring the target tailings lift thickness and, when approaching capacity, design and regulatory freeboards are achieved, has been implemented at Site D. As accessing the tailings beach can be difficult, multi-coloured chains have been affixed to the upstream face of the embankment as shown in Figure 2. The variation in colour denotes the tailings freeboard level in yellow and alternating coloured links spaced at $200 \mathrm{~mm}$ vertical difference to allow operators to gauge when the target lift thickness has been achieved and migrate to the next bank of spigots.

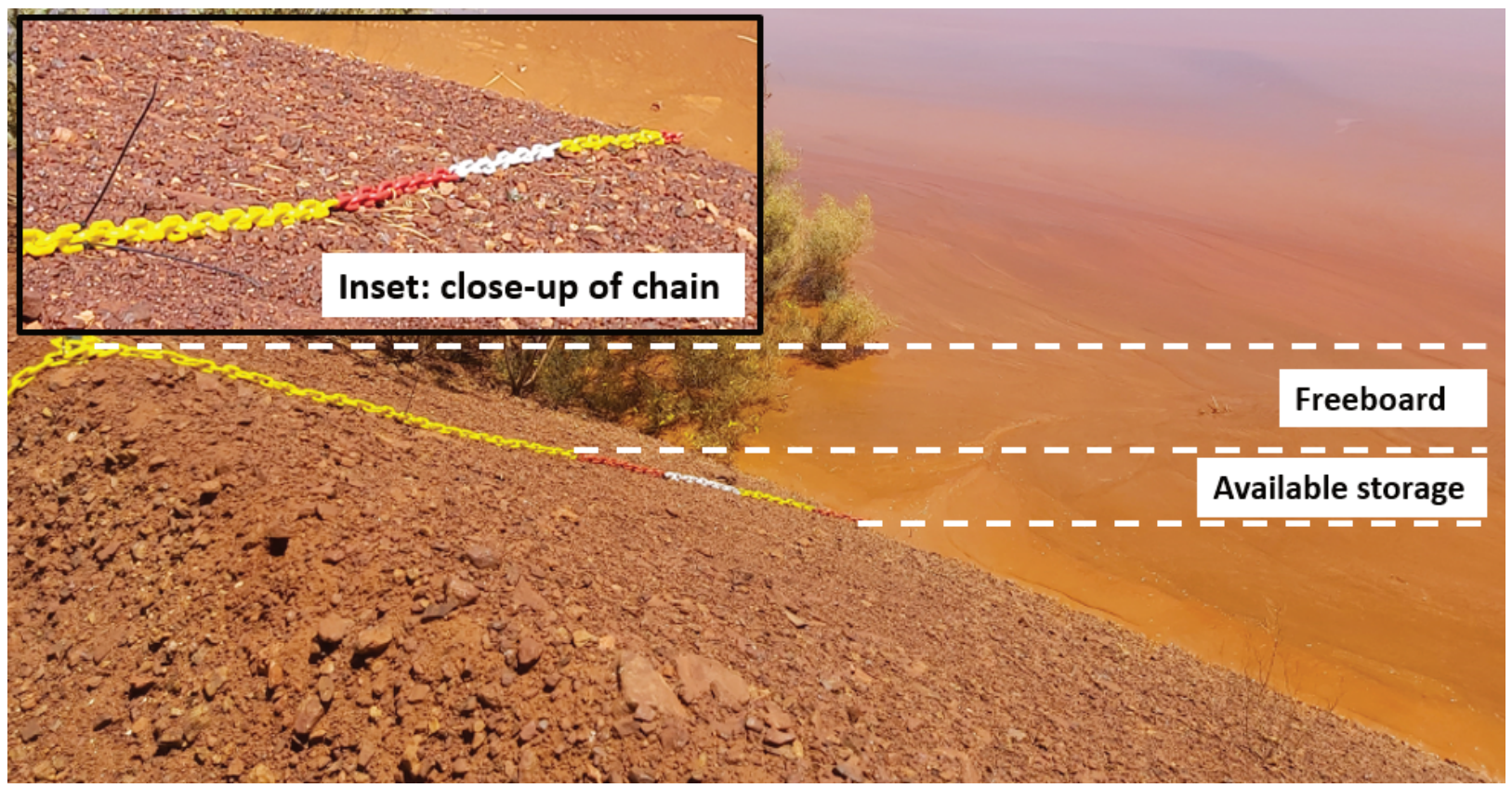

Figure 2 Photo of vertical elevation control chains at Site D 
The examples presented in this section emphasise that the design should be developed while ensuring all operational requirements of the facility are tailored to the site resources, are achievable, and can be effectively communicated to operational personnel. This applies equally to day-to-day operations and responses to undesirable events such that hazards can be readily identified and acted upon by the operational team. Overall, the implementation of detailed deposition planning has reinforced the importance of alignment of the designer and operator.

\subsection{Decant return}

Decant management plays a significant role in overall dam safety. Generally, most TSF failures are associated with or directly caused by excessive water stored in the TSF or in the incorrect location. Every TSF is unique and could pose challenges depending on location, geometry, deposition plan, decant location and method. The last two points are also often time-variable. The objective is to maintain the supernatant pond as small and shallow as practicable by returning water to the plant or elsewhere to reduce issues associated with excessive water storage whilst maintaining flexibility to contain extreme storm events.

The TSF at Site $E$ has experienced multiple decant management challenges. The facility consists of one cell of approximately $100 \mathrm{Ha}$ comprising a paddock facility utilising the terrain of a ridge to the north. Additionally, a central ridge runs east-west through the TSF basin such that saddle dams have been constructed at the northeast and northwest of the impoundment. The decant system is a trailer-mounted, diesel-powered pump, with the collected supernatant and rainfall runoff pumped directly back to the plant. The following decant management challenges have been managed on site:

- The central ridge contributes to most of the issues, including deposited water needing to concentrate from multiple spigots and flow around the ridge to the decant, impacting depositional control.

- Spigots position is located along the embankment crest with uneven distances from the location of the decant pond.

- Increase in return water turbidity during deposition from spigots closer to the pond.

- Lower decant flow rates achieved compared to design assumptions.

- Increase in tailings solids returning to the process water tank.

To overcome the challenges at the TSF at Site E, the following controls have been implemented, which have also reduced overall long-term costs:

- Installation of a floating turret on the suction line and turbidity sensor at the decant pump. The benefits of this are:

- Reclamation of water from the decant pond to depths as low as $0.3 \mathrm{~m}$, reducing pond size and providing additional air drying.

- Reduction of cleaning/maintenance costs to the process water tank by transporting fewer tailings solids back to the plant.

- Reduction in costs for pump maintenance and parts replacement with minimum solids running through the decant pump wet end.

- Decant pump system controlled remotely using the installation of telemetry and solar, which provides the following benefits:

- Enables the pump to be switched on and off on demand (e.g. before or during a forecasted storm event).

- Reduces risk to personnel driving to the pump to operate it during a storm event, noting this particular TSF is $7 \mathrm{~km}$ away from the plant. 
- Deposition plans, including a period of deposition and spigot discharge locations suited to manage the pond location and position, providing the following benefits:

- Assist in management of dam safety risk by mitigating ponding against the embankment.

- Constricting the pond to a particular location or area, increasing drying time for tailings to achieve higher densities and providing a buffer before the wet season.

- Spigots allowed to flow at high velocities to achieve flatter beach angles to enable the farthest spigots to push the pond up the ridge and around the ridge effectively.

- Manage facility effectively with lower decant return flow rates by allowing spigots farthest from the pond to run for longer, allowing evaporation on the beach rather than reporting directly to the pond, reducing evaporation.

- Formalised maintenance plans and daily inspections by operators, with the following benefits:

- Reduction in decant pump downtime and breakdowns.

- Regular top-up of lubrication and fuel increases pump efficiency, longer running cycles and avoiding long-term replacement costs.

At Site $B$, a batch operating strategy of the plant means that decant operations are often only possible around $50 \%$ of the time. This in contrast to an assumed $100 \%$ utilisation in the original design. The facility has also suffered from prioritisation of water from pit dewatering activities over decant return. This is partially due to the inability to return decant water during the early years of the facility and the facility water balance not being built into the overall site water balance. This has resulted in the plant not being reliant on decant water and the subsequent development of control logic that prioritises raw water. Targets for decant return rates have been formalised at all sites such that they are now included in facility TARPs and tracked against actual production data (slurry density, tailings production) to allow for assessment against the overall water balance, rather than design rates. This means that any non-compliance with the water balance can be identified and investigated to determine the causes and actions to rectify. The impact of such governance has been a systemic reduction in pond volumes and a general increase in in situ densities.

\subsection{Water balance models}

Development of water balance models for all operating TSFs commenced in 2017. Some facilities had basic models that were delivered by the designer, but improvements have been made, including in terms of reconciliation to better understand the risk of excess water and how this varies over time. Relatively simple spreadsheet-based models using the same format and coding have since been employed at each site. Although not as mathematically complex as water balance models often developed as part of the process of designing new TSFs, they are designed to allow the operations team to own and understand the data such that they are able to employ proactive management. The models are currently being upgraded to undertake probability-based forecasts by way of Monte Carlo simulation; an addition that is simpler for all to comprehend and action. The results of the water balance forecast for each TSF are reported widely to all stakeholders each month, included in regular discussion with the EoR, and included in the scope of assurance activities completed at frequencies ranging from quarterly to biennially.

The use of the water balance models has assisted in identifying where infrastructure upgrades should be implemented or facilitated agreements with other departments that also own mobile pumps put in place such that additional capacity could be implemented quickly following large rainfall events. Table 3 presents the variation in the estimated time to remove the retained rainfall volume following a 100 -year annual recurrence interval, 72-hour duration rainfall event between 2018, before improvements were implemented, and 2021. The work to achieve this has been relatively simple on most sites. For example, an additional diesel pump with a much higher capacity than the electric pump installed the decant can be installed quickly via an existing ramp from the decant causeway that remains from construction and tied into the return water line via a valved T-piece that has been installed. This nearly doubles the decant capacity and can be deployed 
very quickly as the pump can be rapidly accessed. In this instance, it was fortuitous that the return water line had sufficient capacity to accommodate the increased flows. This is not possible on some other facilities, so emergency discharge locations have been identified downstream of the dam, and in some cases, dedicated pipelines installed as a precaution to ensure excess water could safely be removed in the event of significant rainfall.

Table 3 Comparison of time to remove retained rainfall from a 100 year annual exceedance probability, 72 hour duration storm event on ex-pit TSFs

\begin{tabular}{llll}
\hline & \multicolumn{3}{c}{ Time to remove (days) } \\
Site & TSF & $\mathbf{2 0 1 8}$ & $\mathbf{2 0 2 1}$ \\
\hline \multirow{2}{*}{ Site F } & 1 & 16 & 7 \\
& 2 & 20 & 10 \\
Site G & 1 & 164 & 21 \\
Site D & 1 & 34 & 29 \\
& 1 & 29 & $7-14$ \\
Site E & 2 & 69 & 59 \\
& 1 & 164 & 121 \\
Site A & 2 & 238 & 120 \\
Site C & 1 & 119 & 83 \\
Site B & 1 & 99 & 38 \\
\hline
\end{tabular}

The process of creating and maintaining the water balance models has also highlighted some differences to those developed by designers. For example, the assumption that the decant facility is available $100 \%$ of the time. This has proven unrealistic, except in cases where a duty and standby arrangement is employed; however, even in such cases it is recommended $100 \%$ not be assumed unless robust maintenance tactics are in place and carried out. Another input to the models is minimum pond depth to allow pumping. Some technological advances have allowed the suction inlet to operate in ponds as shallow as $0.3 \mathrm{~m}$ successfully, but previously designs such as floated high density polyethylene pipe routinely required $2 \mathrm{~m}$ pond depth to avoid mobilising tailings solids. The $1.5 \mathrm{~m}$ difference between the two techniques correlates to a significant pond volume for most facilities. Accurately defining the beach angles assumed in the water balance is also important. Improvements in deposition slurry density (see Section 5) and improved water management more broadly appear to have resulted in steepened beach angles by an average of around $0.1 \%$ on several facilities to date. Although this sounds minor, it correlates to an increase in stored water volume for the red trigger level (highest alert in the TARP) of 11-18\% across ex-pit TSFs in the portfolio. This highlights the impact that input assumptions can have on the outputs and usefulness of a water balance.

\section{$5 \quad$ Results}

The achievements outlined in the case studies have generally presented either a risk mitigation or financial benefit, as discussed in this section.

\subsection{Risk mitigation}

The reduction of risks that has occurred as a result of the case studies presented mostly relate to improvements in water management. Shortcomings in this area have often contributed to the TSF failures reported in the literature (International Committee on Large Dams 2001; Azam \& Li 2010; Rico et al. 2008; 
Clarkson \& Williams 2021). A summary of key elements achieved that related to risk mitigation through reductions in the probability of failure include:

1. Reduced water deposited in slurry.

2. Increased decant return rates.

3. Increased beach lengths and angles, increasing storage before the pond poses a dam safety threat.

4. Better shaped beach profiles to maintain the pond central to the decant, facilitating 2 and 3.

5. Increased agility to respond to storm events quickly and efficiently.

6. Ability to forecast future issues related to water volume stored on the facility.

In addition, the increase in slurry density is likely to have increased static shear strength, post-seismic shear strength, and rheological yield stress. This assists in mitigating probability of failure risks and the mobility of a failed tailings mass, resulting in a lesser inundation area and associated consequences of a hypothetical failure. Therefore, the actions described in this paper have bolstered the pre-existing risk management practices of each TSF, further reducing both the likelihood and consequences of failure.

\subsection{Deferral of capital expenditure}

Dam safety was the primary goal of all the actions taken in the case studies presented. However, a fortuitous by-product has been widespread deferral of capital expenditure required to expand many of the TSFs in the portfolio through improved in situ dry densities. Table 4 presents a summary of change of measured in situ density of tailings between the start of 2019 and end of 2020. The densities presented are 'instantaneous', the average density of the tailings deposited over a three-month time period, without allowance being made for overall settlement of the underlying tailings mass, which is thought to be a relatively small contributor to the net change in density observed. Measurement of tailings volumes is via LiDAR scans taken either by fixed-wing aircraft or drones. As a result, the sustaining capital expenditure required each year is reduced by a similar percentage to that of the density increase.

As stated earlier, the improvements presented are largely the result of work completed by a relatively recently mobilised tailings team. Although this is a net increase in overhead costs associated with management of the portfolio of TSFs, the capital deferrals experienced in less than two years are significantly greater than the cost of employing the team.

Table 4 Summary of improved in situ dry densities

\begin{tabular}{lll}
\hline Site & In situ dry density $\mathbf{2 0 1 9}\left(\mathbf{t} / \mathbf{m}^{\mathbf{3}}\right)$ & In situ dry density $\mathbf{2 0 2 0}\left(\mathbf{t} / \mathbf{m}^{\mathbf{3}}\right)$ \\
\hline Site A & 1.50 & 1.82 \\
Site E & 1.03 & 1.45 \\
Site C & 1.90 & 2.19 \\
Site B & 1.37 & 1.60 \\
\hline
\end{tabular}

\section{Conclusion}

While challenges exist in the absence of a widely accepted definition of the term 'design intent' in the tailings industry, it is broadly understood. Articulation of quantitative goals in place of relating non-compliance to a failure to achieve the 'design intent' is suggested as an improvement opportunity. Referencing the broad understanding of the design intent, this paper has demonstrated initiatives implemented during the operations phase of several TSFs that have assisted in achieving the design intent, and subsequently improving the safety of the portfolio of TSFs, and in some cases, even presented a financial benefit. 


\section{Acknowledgement}

The authors acknowledge Rio Tinto for allowing the learnings they have taken from their work to be shared.

\section{References}

Australian National Committee on Large Dams 2019, Guidelines on Tailings Dams Planning, Design, Construction, Operation and Closure, Australian National Committee on Large Dams, Hobart.

Azam, S \& Li, Q, 2010, 'Tailings dam failures: a review of the last one hundred years', Geotechnical News, vol. 28, December 2010, pp. 50-53.

Clarkson, L \& Williams, D 2021, 'An overview of conventional tailings dam geotechnical failure mechanisms', Mining, Metallurgy \& Exploration, vol. 38, no. 3, pp. 1305-1328.

Department of Mines, Industry Regulation and Safety 2021, How is Safe Design Verified?, Perth, viewed 25 April 2021 , http://www.dmp.wa.gov.au/Safety/How-is-safe-design-verified-4808.aspx

Global Tailings Review 2020, Global Industry Standard on Tailings Management, viewed 12 April 2021 , https://globaltailingsreview.org/global-industry-standard/

Geoprofessional Business Association 2018, Proposed Best Practices for the Engineer of Record (EOR) for Tailings Dams, Geoprofessional Business Association, Rockville.

International Committee on Large Dams 2001, Tailings Dams: Risk of Dangerous Occurrences - Lessons Learnt from Practical Experiences, bulletin 121, United Nations Environmental Programme Division of Technology, Industry and Economics, and International Commission on Large Dams, Paris.

International Organization for Standardization 2005, Industrial Automation Systems and Integration - Product Data Representation and Exchange - Part 108: Integrated Application Resource: Parameterization and Constraints for Explicit Geometric Product Models (ISO 10303-108), International Organization for Standardization, Geneve.

Liu, J \& Sun, Z 2008, 'Representing design intents for design thinking process modelling, in XT Yan, WJ lon \& B Eynard (eds), Global Design to Gain a Competitive Edge, Springer, London, https://doi.org/10.1007/978-1-84800-239-5_1

Mining Association of Canada, 2021, A Guide to the Management of Tailings Facilities Version 3.2, Mining Association of Canada, Ottawa.

Morgenstern, NR, Vick, SG, Viotti, CB \& Watts, BD 2016, Fundão Tailings Dam Review Panel: Report on the Immediate Causes of the Failure of the Fundão Dam, viewed 11 August 2021, https://www.resolutionmineeis.us/documents/fundao-2016

Rico, M, Benito, G, Salgueiro, AR, Diez-Herrero, A \& Pereira, HG 2008, 'Reported tailings dam failures a review of the European incidents in the worldwide context', Journal of Hazardous Materials, vol. 152, pp. 846-852. 